\title{
تعدد الرؤى الاخراجية للموضوعة الواحدة في الفيلم القصير
}

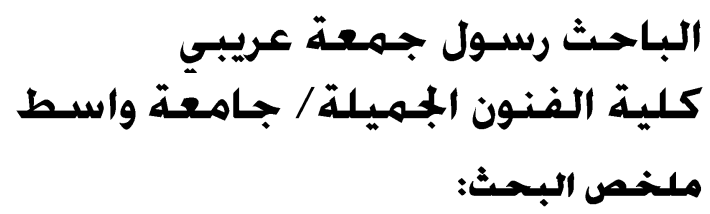

جاعت هذه الاراسة نتيجة التطور الحاصل في السينما او الفيلم القصير بالتحديد بوصفه شكلاً او نوعاً من الافلام السينمائية والذي لا يقل اهمية عن غيره حيث انه يتمتع بكبان خاص به على مستوى البناء وعلى مستوى التجسيل مما جعل العاملين في هذا الحقل الى الابتكار في تناول الموضوعات ضمن هذا النوع فأنثارت الباحث الافلام التي انتجتها شركة (BOMBAY SAPPHIRE) حيث منحت فكرة الفيلم فقط الى مخرجين متعددين وطلبت منهم كتابة سيناريو واخراجها كلاً حسب رؤيته بالتالي سنحصل على تجارب ورؤى مختلفة لموضوعة واحدة مما يستوجب دراسة هذا الشكل الفيلمي للوقوف على ما حقّته تلك الأفلام من جماليات تعبير عبر توظيف عناصرها التعبيرية في حدود التجريب. اذ جاءت هيكلية البحث في اربعة فصول كالاتي:

الفصل الاول ـ الاطار المنهجى: تناول هذا المحور مشكلة البحث التي تبحث عن الكيفية التي خلالها نتعرف على الرؤى المتعددة للموضوعة الواحدة في الفيلم القصير ، كما تضمن الفصل أهمية البحث و الحاجة اليه، كنلك الهذف منه، ثم الحدود و تحديد المصطلحات. : الفصل الثانى ـ الاطار النظري: تألف من مبحثين :

(المبحث الاول) البناء الدرامي في الفيلم القصير ، اما (المبحث الثاني) فقد جاء بعنوان : المخرج وعناصر الاشتغال السينمائية الفصل الثالث / إجراءات البحث: واحتوى على: منهج البحث ،مجتمع البحث ، عينـات البحث ، أداة البحث في المؤشرات المستخلصة من الإطار النظري بعد عرضها على لجنة من الخبراء المختصين لتقويمها ،كذلك وحدة التحليل )

BOMBAY الفصل الرابـع: تضـن هذا الفصل تحليل عينـات البحث القصدية في (اربعة افلام) تم اختيارهـا مـن (الثركة المنتجـة (SAPPHIRE وخرج الباحث بمجموعة من النتائج والتوصيات والمقترحات وختم بقائمة المصادر .

Research Summary:

The film was produced by BOMBAY SAPPHIRE, who gave the idea of the section only to two directors, several characters and script guides, and directed them based on their experiences. The film was based on other experiences and visions for one set. This film has to be studied to determine what the films are entitled to. Expression funds through the recruitment of elements in the field of experimentation. The three structure of research in four chapters is as follows:

Chapter 1: The Methodological Framework: This topic deals with the problem of research, which seeks how to identify the multiple visions of one position in the short film. The chapter also includes the importance of research and the need for it, as well as the goal,

Chapter II - Theoretical framework: It consisted of two sections:

(The first subject) drama construction in the short film, while (the second section) was entitled: the director and the elements of cinematography

Chapter III: Research Procedures: The research methodology, the research community, the research samples, the research tool in the indicators derived from the theoretical framework after being presented to a committee of specialized experts to evaluate them,

Chapter Four: This chapter included the analysis of the samples of the intentional research in (four films) selected from the company (BOMBAY SAPPHIRE) and the researcher came out with a set of conclusions, recommendations and proposals and a list of sources. 


\section{الفصل الاول ـ الاطار المنهجي}

أولاً : مشكلة البحث: ان در اسة الرؤى المتعددة لاكثر من مخرج لنص واحد في غاية الاهمية كونها ستتتج تجـارب مختلفة تتحكم فيهـا المرجعيـة الفكريـة ومستوى الوعي للمخرج و الكيفيـة التي يجسـ فيهـا هذا النص

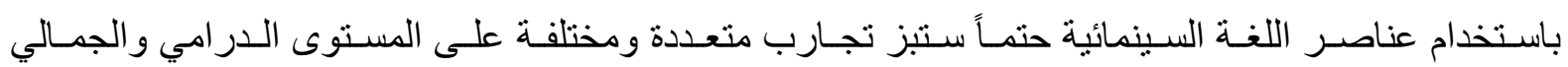
وبالاخص لو كانت الافلام تجريبية قصيرة وبالتالي تكمن مشكلة البحث في السؤال الاتي ( ما هي الكيفية الذي وهي

تتحقق من خلالها روئة كل مخرج للنص الواحد في الفيلم القصير)

ثانياً : أهمية البحث :- ان هذه الدر اسة تهم الدارسين و الباحثين في مجال السينما كالمخرجين وكتاب السيناريو ،

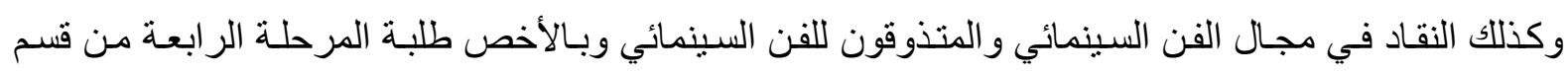
الفنون السينمائية عندما يقومون بصناعة اول تجربة لهم فعن طريق تتـاول كل مخرج للنص سنعرف مستوى الخبرة و المعرفة التي اكتسبها الطالب اثثاء الدراسة.

ثالثاً : أهداف البحث :- يهدف البحث الى التعرف على الرؤى المتعددة للموضو عة الواحدة وكيف تم تجسيدها صورياً بواسطة عناصر الاشتغال وفق رؤية محددة .

رابعـاً : حـدود البحـث :- يتحـدد البحـث بدارسـة الافـلام القصـيرة التي انتجتهـا شـركة ( BOMBAY

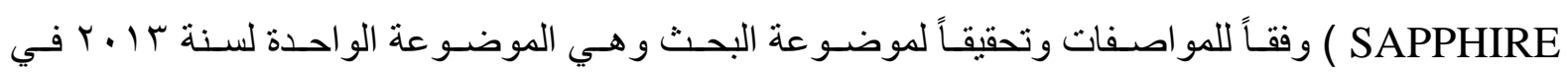
بريطانيا.

خامسا: تحديد المصطلحات :

الرؤيا الاخراجية : الرؤيا ذكرت في كتاب( المنجد في اللغة ) على انها ما يُرى في المنـام ، و ايضـاً كلمـة الرؤيـا

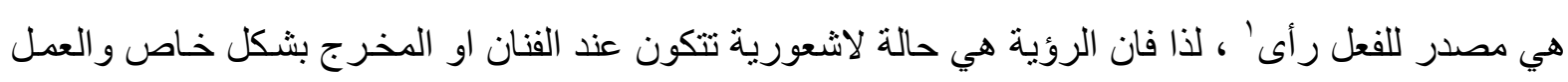
السينمائي لا يمكن له ان يخلو من الرؤيـة لان السينما واحدة من اهم الاعمـال الفنية التي تتخلاهـا الرؤيـا بشكل

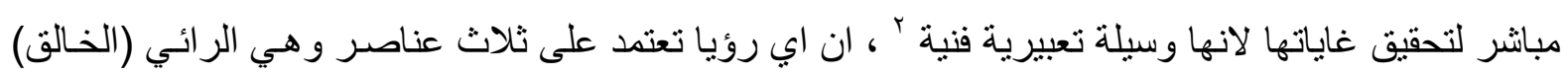
بذكائه و عبقريته وحسه وثقافته ومعتقداته وشعوره بالانتماء والعنصر الثاني هو الو اقع الاجتماعي و الاقتصـادي وقوى التحريك في هذا الو اقع اما العنصر الثالث فهو التوجه الخالص للخالق من خلال طموحسه وقدراتـه وتمكنه من ادو ات خلقه وما ان تصل الرؤيا الى المتلقي بوسـائلها وتأخذ الرؤيا طريقها على مر احل ابتداء من ادراء الك وتصور المخلوق حتى تكامل العمل الفني ونضوجه ووصوله الى المتلقي ‘ ـ وفي مقالة نشرتها مجلة الاكاديمي للاكتور(جعفر علي) بعنوان ( الرؤيا في الفن العربي : السينما والمسرح) نطرق لموضوع الرؤيـا في السينما

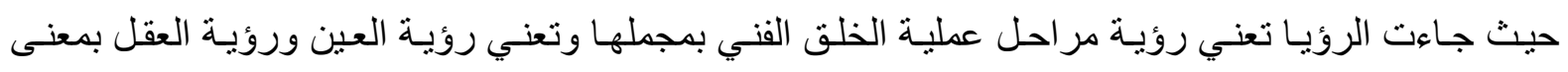
التفكير ، ورؤية الثعور بمعنى الاحساس المرهف بالمعاني ورؤيسة المستقبل بمعنى التتبؤ والتمني و الاستتناج

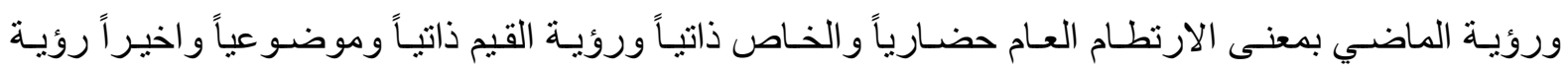
المخلوق الفني قبل و لادته بمعنى ادر اك امكانية موضو عيته وفق مو اصفات محددة طبقاً لقيم موضو عية فنية مرتبطة بتطور تاريخي محدد ؛ 
و الرؤيا الاخر اجية على ضوء مـا تقدم هي الاحسـس و الادر الك والتنبؤ بكل تفاصيل العمل السينمائي

و الكفية التي يروي فيها المخرج قصته فكل الاضـافات التي يضيفها المخرج الى الفلم او النص مـاهي الا من افر ازات الرؤيا ـ فالرؤيا من اهم المو اهب التي يجب تو افرهـا في المخرج رغم تفاوتها من مخرج الى اخر ،

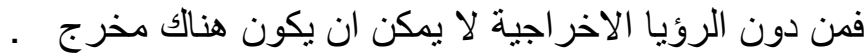

\section{المبسحث الاول - البناء الدرامسي في النفلهم التقمير تعريف الفيلم القصير}

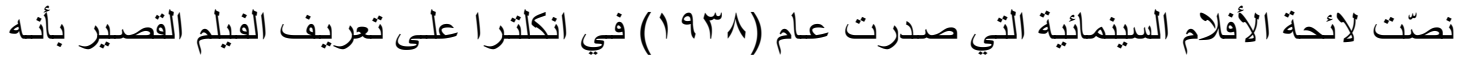
الفيلم الذي يقل طوله عن ثلاثة آلاف قدم في زمن (rس) دقيقة كما في الرسوم المتحركة و الجريدة السينمائية

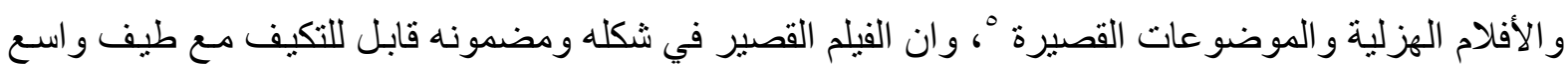
من الاهداف الجمالية و انه يعالج لحظـة مثلمـا تفعل الصورة الفوتو غر افيـة ويعالج حالـة عاطفية ومز اجيـة منلمـا تفعل القصيدة او ملحوظة تأملية عميقة كما تفعل القصـة القصيرة " ، وفي الولايـات المتحدة يطلق على الافلام القصبرة مصطلح الموضو عات القصيرة الذي تبلغ مدتها حوالي (•r) دقيقة وهو بذلك بشبه الافلام الموجزة او الافلام التسجيلية التي يصنعها الطلاب في اطروحاتهم ومشاريع التخرج ` وكان احد اهم الأفلام القصبرة في كل تاريخ السينما رد فعل على تقاليد السينما الرؤاثية في العشرينيات وتجربـة منأثرة بالافكار التي اكتشفت في عالم الفنون البصرية (السريالية على نحو خاص) وايضـاً بمفردات المذهب الكاثوليكي في اسبانيا وكان هذا الفيلم هو (كلب اندلسي) الذي اشترك فيه لوئ بونويل وسلفادور دالي ^ ، ولقد تعددت تعاريف الفيلم القصير وكثر الاختلاف حول هو يته الفنية والتقنية، فهو تمرين على التقنيات والأساليب السينمائية على حدّ سواء، واخر ير اه مجرد مرحلة عبور إلى الفيلم الطويل، الفيلم القصير فيلم قائم بذاته، لـه فلسفته وهويته الفنيـة، بغض النظر عن مدته الزمنية.

ان مصطلح القصير المـلازم للاسم رغم الاختلاف في الر أبي المتباين بغناهـا ورؤاهـا، يرى المخرج (مؤمن السميحي) "أن الفيلم القصير ليس تقزيما ولا تحقيرا، ليس القصير استر اتيجيا، ليس القصير نمطا، ليس القصير تمرينـا ولا ترويداً ، ليس القصير مقدمـة تجاريـة للطويـل، ليس القصير مدرسيا، و لا هو اختصـار

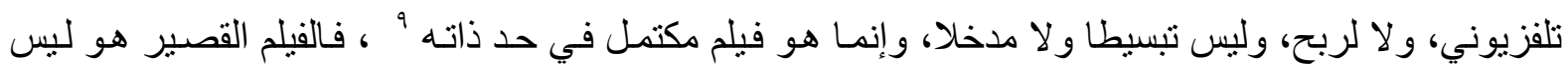
قصـة ولا قصيدة، ولكن حكي بصري على وفق قو اعد سينمائية عامـة، وبنـاؤه يتطلب تركيز ا على مستوى التركيب الدر امي و التقني و الحمولة الوجدانية والادر اكية حتى لو كان زمن الفيلم لا يتعدى الدقيقة الواحدة وان الفيلم القصير في النهاية يتميز بالعديد من المقومـات التي تجعل لـه خصوصية ومكانته التامـة، فالفيلم القصير تميز بأنه يحذف الاستطالات و الازمنة الغير مهمة، وييقي على الضروري لنمو الحدث وتطوره ممـا يجعل لهذا النمو خصوصية، ويلفت إليه الانتباه ' . كما يرى-كين دانسـايجر-وبات كوبر"على إن الفيلم القصير يشترك

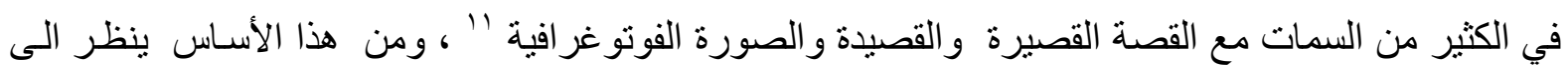
الفيلم القصير في مرحلـة صناعته على "ان الفيلم القصير يقع في منطقة مجـاورة للأنواع الفيلميـة الأخرى المهمة وبقدر تجاوره معها فأنه بأخذ منها، فهو مثنا يأخذ من الفيلم الوثائقي بعضـا من و اقعيته وربمـا الأمساكن 
و الثخصيات الحقيقية التي بستخدمها وتعد خصوصية خاصـة بـه وهو يتفاعل مـع الفيلم الرو ائي الطويل ويأخذ

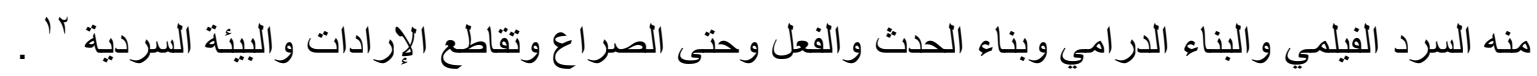
نستتنج من هذا ان الفيلم القصبر يتضمن حدث واحد وفي مكان واحد او امكنة قليلة مرتبطة مع بعض بشكل وثيق و عدد الثخصيات قليل وفي الاغلب شخصية واحدة وبالتالي فان زمن الفعل سيكون قصير اً مما يحد من الخوض في التفاصيل للشخصيات و الامكنة.

بناء القصة

منذ العصور القديمـة ظهرت نظريـات ودر اسـات في علم الدر اما كانت كثيرة الـى درجـة انها كانت تتناقض فيما بينها ولا شك ان ارسطو قارب الحقيقة الى حد كبير عندما كان يؤكد ان القصة يجب ان ترتكز الى

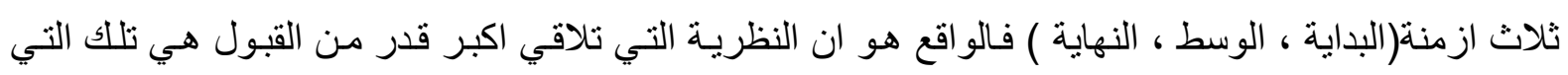
تقول بالفصول الدر امية الثلاثة " . ان الكاتب الذي يبني قصته بناء محكماً لا يملك الحرية في ان يبدأ او ينتهي

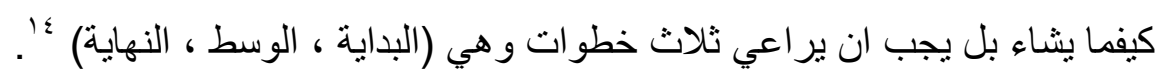
البداية:

فتعريفها انها الثي الذي لا يجب ان يسبقه شيء وفي نفس الوقت يتطلب ان يلحقه شيء ، فالبداية ليست عرضاً او مقدمة انها مرحلة من مر احل الحدث تحتم ان يتبعها شئ معين اي انها شئ يترتب عليه حدوث شئ

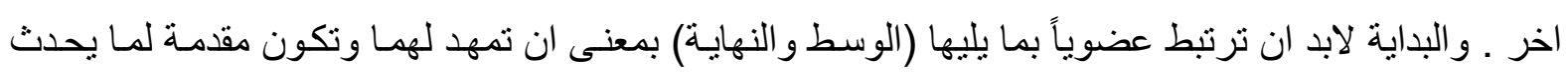
فيهما وبحيث يكون ما يحدث بعدها نتيجة لما وقع فيها وبحيث لا يحدث بعدها شئ يتناقض مع ما ورد فيها 10. ويرى ارسطو ان البناء الدرامي الامثل هو الذي لا يمكن ان تقع فيه البداية (التقديم او العرض) ابداً بعد الوسط

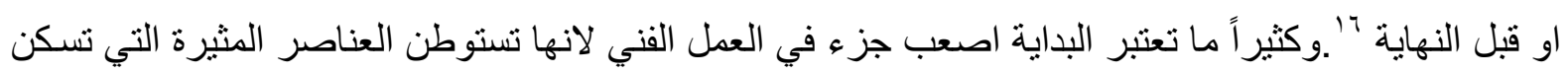

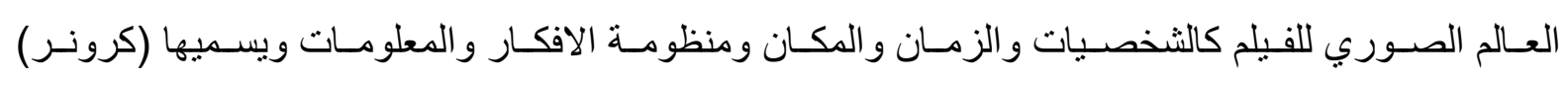

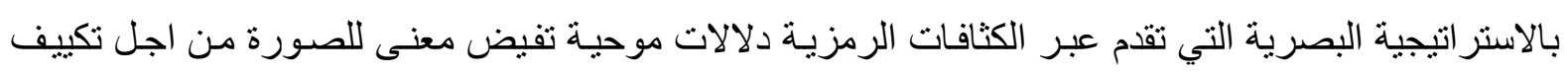

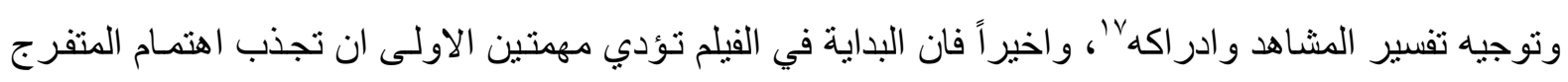

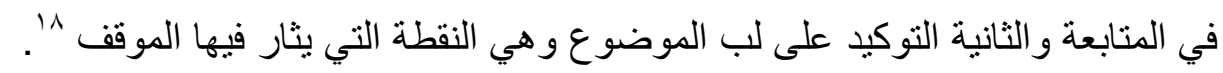

الوسط:

البناء الدرامي يحتوي على بدايـة فيها تمهيد للاحداث الخاضعه لقانون (الضـرورة او الاحتمـال) يليها الوسط الذي يحتوي على عرض لهذه الاحداث وتفصيل دقائقها فالوسط (التطور) هو مرتبط تماماً بما قبله وبما بعده بحيث ان ما قبله وهو البداية يؤدي حتما الى وجوده وبحيث يؤدي هوة نفسه الى وجود ما بعده وهو النهايـة 9. و والوسط يكثف عن الخطوات المختلفة لصر اع الثخصية لتتغلب على المخاطر التي شهدها ، تملؤ هـا افكار جديدة وتغيرات مفاجئـة ومثيـرة ومشـاعر غزيـرة ـ وفي الوسط تتماسـك اجز اء الفعل وتتفاعل الثخصـيات

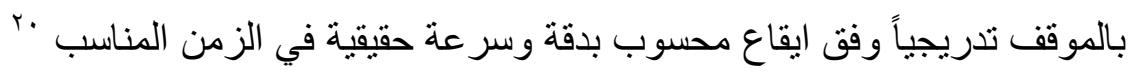


هي الجزء الذي يرتبط عضوياً بكل من الوسط و البداية ويكون نتيجة حتمية لكل منهما ولكن رغم وقوع

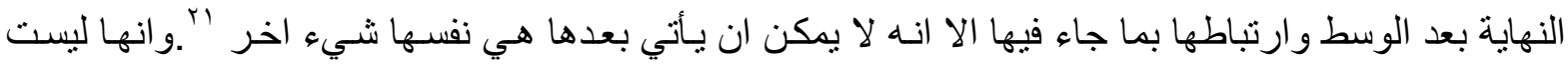

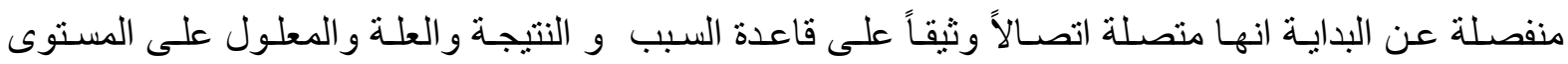
الدرامي ففيها نهاية الصر اع والوصول الى الهدف و الحل و الاجابـة عن تسـاؤلات البدايـة ـ فهي بؤرة التطهير

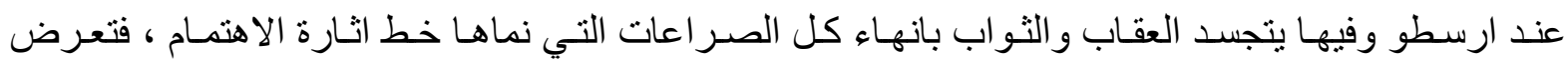

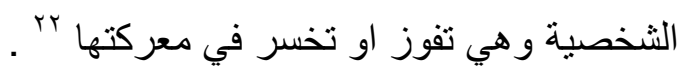

اذاً نكتشف ان هذه الاجزاء الثناثتة يجب ان تكون متر ابطة نز ابطـاً وثيقاً حيث ان كل جزء منها قائم بذاته و لا يقل اهمية عن الاخر وهذا الترابط هو الذي يدفع القصـة الى الامـام من خـلال ترتيب الاحداث بشكل منطقي متماسلك يخلق من خلاله تقديم الاحداث ونشؤ الصر اع بين الاطر اف المتناز عة وصولاً الى ذروة الحدث ثم تأتي النهاية (الحل) وينتهي الصر اع ويتجسد العقاب و الثواب.

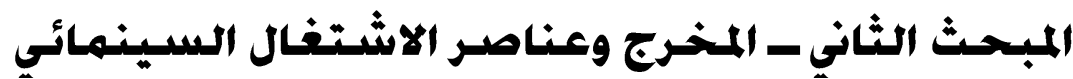

ان لكل مخرج سبنمائي منظور خاص ومستقل ونظرة تجـاه الاشياء و هذه النظرة تأتي من التجربـة و الثقافة والخبرة الثخصية و الو عي مما يجعل المخرج يتبنى اختيار ات بعينها دون الاختيارات الأخرى تنعكس بدور ها على تجسيده للنص الفيلمي وتصبح من البديهيات وبالتالي ستصبح عنده فلسفة خاصـة ينتج بها الفيلم و هذا من حقه كونه المنتج الرئيسي .

و الفلسفة الاخر اجية هي رؤيـا استسـاغها المخرج من بـاطن العقل حسب خبرته الفنيـة ورؤيته للأنتاج

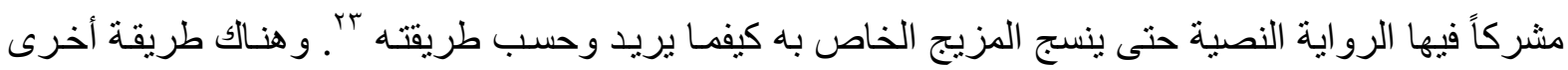
لتطوير فكرة المخرج و هي العمل على تأكيد معنى متضمن في القصـة ففي فيلم (كل شيء عن حو اء) المعنى

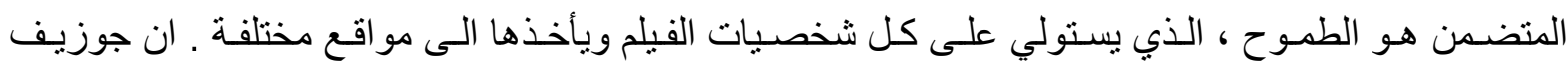

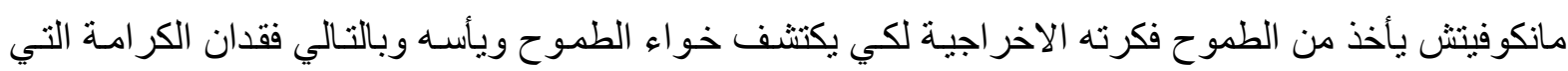

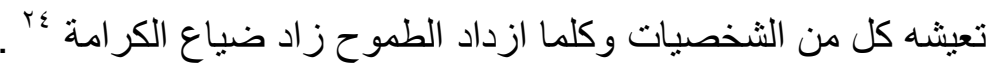

وبالتالي يجب ان تكون هناك فكرة خاصة للمخرج ضمنية داخل الفيلم فكرة عميقة تمثل قيمه الخاصـة

و هو اجسـه تجـاه الحيـاة ، امـا تطرح تسـاؤلات او تجيب على تسـاؤلات حياتيـة عامـة تخص المخرج او الجهـة المنتجة سواء كانت دولة او مؤسسـة او اشخاص فعلى مستوى الاثخاص مثثلاً نجد ان في اغلب افلام ستيفن سبيلبرك يحساول ابر از قضية المظلوميـة اليهوديـة في افلامسه من خـلال مشــاهد صورية رمزيـة او من خـلال الحوار ـ لذا فان فكرة المخرج هي تفسير عميق لكل ما يتضمنه النص ولا يصرح به و هذه التفسير هو مـا يخلق

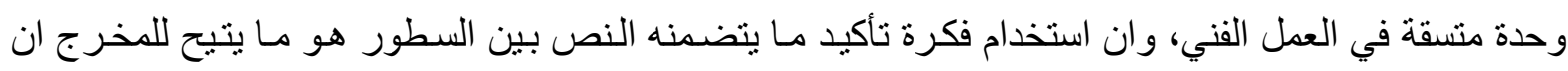
يعبر عن تناول اخر اجي يضيف الكثير الى أداء الممثلين او استخدام الكاميرا، وان مدى اصـالة فكرة المخرج هي التي تميز بين المخرج الذي يكتفي باجادة الحرفة والمخرج الجيد والمخرج العظيم ، وفكرة المخرج هي التي تقوده لاتخـاذ مختلف القرارات خـلال عملية صنع الفيلم ْب. فـان الوعي بفكرة المخرج هو نقطة البدايـة 
لتطوير العملية الاخر اجية فهناك مخرج حرفي يكتفي بان يعثر على طابع واحد للسيناريو الذي يخرجه قد يكون الرومانسية او العنف اما المخرج الجيد فانه يعطي رؤية اكثر تعقيداً للنص تحتوي على عدة طبقات من التفسير بينما يحول المخرج العظيم نص السيناريو الى مستوى من الإيحاء المدهش يتجاوز النص نفسـه بَّ ، ففي فيلم (سارق الدراجـة) لدسيكا فيرتوف في ان هنـاك رجل يستخدم در اجته في عمله لكنها تسرق منـه ممـا يعرض

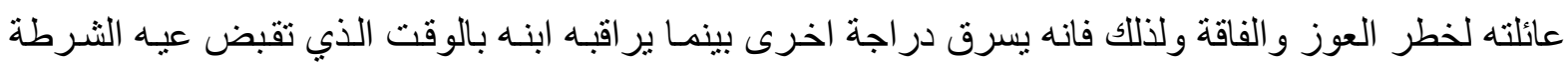

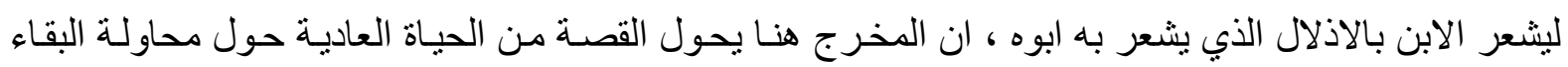

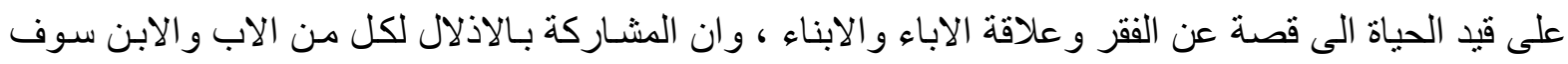
تترك اثرها في الطفل وتطرح تساؤ لات كثيرة حول مستقبل الطفل ، وهذا بالضبط مـا يفعله المخرج من خـلال فكرته الاخر اجية. وبالتالي فان بقدر زيادة وعي المخرج بفكرتـه وكيفيـة تطبيقها فان العمل الفني سوف يصبح اكثر وضوحاً وجودة وقوة.

\section{المخرج يبدأ في تطوير فكرته الاخر اجية من خلال :}

1 ـ تفسير النص: مـاهو المفهوم الأساسي او المقدمة المنطقيـة الأولى للقصـة؟ ومن الأفضل ان ننظر الى المقدمة من خلال اختيارين متعارضين يو اجهان الثخصية الرئيسية :فالحب و المـال هو الاختيـار الذي يواجه الثخصية الرئيسية في فيلم تايتنك، فالخطوة الاولى في طريق تطوير الفكرة الاخر اجيـة هي قر اءة السيناريو وتفسيره فكل قصـة وكل سيناريو يمكن تفسيره بالعديد من الطرق و هنـا يضيف المخرج اهنمامته وشخصيته وتفسيره للنص "Yr. ان في كل قصة توجد العديد من التفسيرات واياً ما كان التفسير الذي يقدمه المخرج الداخلي ، النفسي ، او الصر اع بين الاجيال او الصراع داخل العائلة او التفسير السياسي فـان النقطة شديدة الاهميـة هي

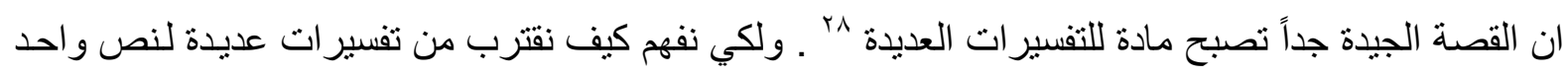
فانه يجب علينا ان ندرس ماذا يضع المخرجون في اعتبـار هم عندما يصنعون تفسير هم الخـاص للنص ـ فأو لاًا

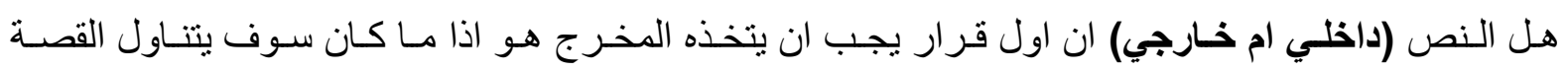
باعتبار ها نفسية داخلية فهي تهتم بالعناصر النفسية لثخصياتها مثل الحياة الداخلية والقيم الروحية او البحث عن القيم او معنى اعمق ، ام انها قصـة خارجيـة تعتمد على سلسلة الاحداث التي تدور في العـالم والاحداث التي تشكل تصرفات الثخصية. بُ وبعض المخرجون قادرون على التركيز على الحدث الخارجي بدون التضحية

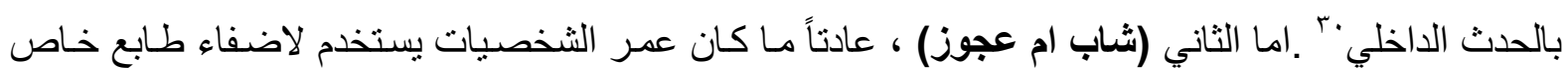
على قر اءة النص فمن الموضو عات التقليديـة ان الثباب يتضـمن الحمـاس او التفائل بينمـا يمثل العمر المتقدم مشاعر الندم او التأمل وتلك هي القراعة المتوقعة لكن استخدام الطرق المتوقعـة او غير المتوقعـة تعطي دائمـاً نتائج جديدة وطازجة ، و أياً ما كان المرء يغير المنضور من الثباب الى العجوز او العكس فـان هناك فرصـة فئس و اضـحة لكي تصنع حكايسة تأسسى للماضـي وتحولها الى المسحة الحيويـة او ان تجعل من حكايـة شـابة مفعمـة بالحماس حكاية متأملة تدور في عالم ضيق وفي كلتا الحالتين فـان فرصـة ادهاش المتفرج تبرر استكثـاف هذا الخيار 'ب ، اما الثالث ( ذكر ، انثى) ان مسألة قر اعة النص على انه صر اع بين ذكر او انتى اكتسب اهمية كبيرة و اصبح من اهم القضايا الاجتماعية والنفسية والسياسية في الزمن الحاضر ، ام مفهوم تطبيق تفسير النص من 
خلال هذا الصـر اع بين الرجل و المر اءة ييدو ذكياً فالرجال والنسـاء لا يرون الاحداث و الثخصيات بالطريقة نفسها ومن ثم فان حكاية قصة رجل من وجهة نضر امر أة او حكاية قصـة امر أة من وجهة نظر رجل او ربمـا

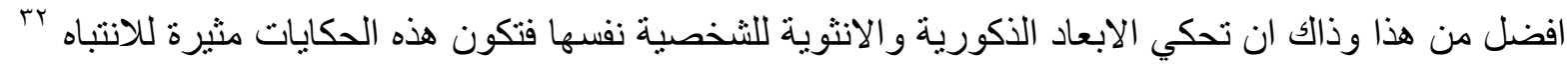

اما الاعتبار الرابع والاخير الذي يأخذه المخرج بعين الاعتبار في مرحلة تفسير النص هو ( السياسي ، الاجتماعي، النفسي) ، ان كلاً من المنظور السياسي والاجتماعي والنفسي هي ادوات يختار من بينها المخرج لكي يقدم تفسيره الخـاص لتتنج عن كل حالة تجربـة مختلفة للسرد الفيلمي ـ فان لكل قصـة ضـلالها السياسي والاجتماعي و النفسي ولكن المخرج يضـع اعتبار ات بعينها لكي يحدد اذا مـا كان الجمهور الذي يرى القصـة سوف يدركها على انها قصة عالمية او قومية او محلية او شخصية وهذا ما يعتمد تماماً على اختيار ات المخرج

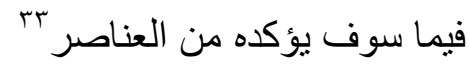
كـ ـ البنية الصورية : ان الصورة هي المادة الاساسية للغة السينمائية فهي المادة الخام الفيلمية وان كانت مـع

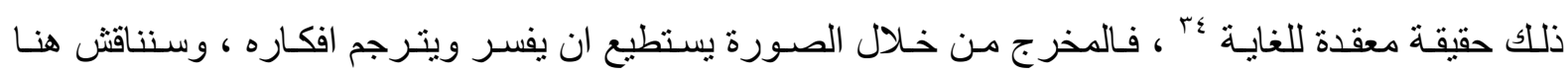
عناصر الصورة من اختيار اللقط واحجامها والعناصر التي نؤثر في طبيعـة اللقطة مثل الاضساءة والمنـاظر وزوايا والتصوير وحركة الكاميرا والاكسسوار وكذلك نتناول تقنية الصوت بدور ها احد العناصر المهمـة ونختم بالمونتاج. اذاً لكي يكون المخرج جيداً يجب ان تكون لديه فكرة اخر اجية يعمل على تنفيذها باستخدام قدر اته في

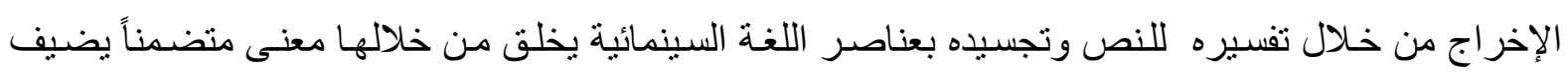
بدوره عمقاً لتجربة مشـاهدة الجمهور للفيلم لان المتفرج يرى الفيلم باعتباره تجربـة متكاملة ومتناسقة تتحد بها جميع العناصـر من تفسير للنص واختيـار ممثلين وعناصـر اللغـة السينمائية وان الوحدة والاتسـاق يعنيان ان أدو ات الإخر اج تعمل معاً وهذا هو هدف الفكرة الاخر اجيـة الواضحة والقويـة التي تعزز وحدة تجربـة مشـاهدة الفيلم و اتساقها.

\section{مؤشـرات الاطار النظري}

من المبحثين السـابقين تكونت مؤشر ات نستطيع من خلالها ان نؤشر مـا حساول البحث ان يتصدى لـه

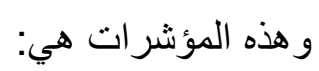

ا. . ان لكل مخرج سينمائي شكلاً مبتكراً يختلف عن الاخر في تتاول مفردات اللغة السينمائية وهي كل مـا يشنمل عليه الفلم التي تقيدنا كثيراً في تحديد رؤية المخرج.

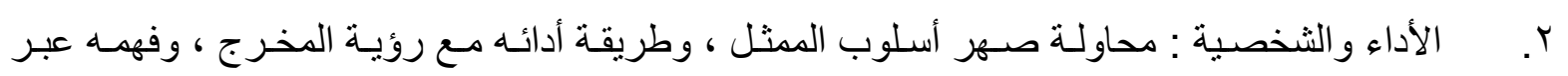
الكيفية التي بريد من خلالها أن يقدم تللك الثخصية على الثاشة r. . التكوين بوصفه مصدراً مهماً للمعلومات والإيحاءات ، و الذي يقصد به كل ما موجود داخل اللقطة و لا يقصد به تحديد التكوين التشكيلي للقطه بقدر ما هو طبيعة استخدام عناصر التعبير السينمائية 
ع. تعميـق المعنى ، وهـو الجانب الأكثر أهميـة في تحديد رؤيـة المخرج السينمائي من حيث توظيفهـ لعناصر اللغة السينمائية •. ان كل من المنظور النفسي والسياسي والاجتماعي هي كلها ادوات يختار من بينها المخرج لكي يقدم تفسيره الخاص لنتتج عن كل حالة تجربة مختلفة للسرد الفلمي.

\section{الدراسـات السسابقة}

لم يجد الباحث أي دراسة تتناول او تقترب من موضوعه (تعدد الرؤى الاخراجية للموضوعة الواحدة

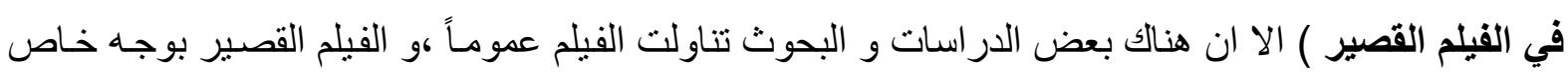
استخلص منها الباحث المقاربات بما بمكن الافادة منها في بحثث، ومن بين هذه الدراسات:

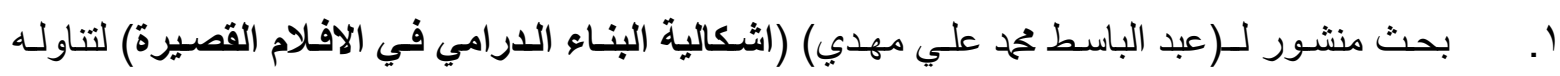
موضوع الافلام القصيرة و احتوائسه مفردات مهمـة في تحليل بعض النــاذج الفيلمية الروائية القصيرة، تنـاول

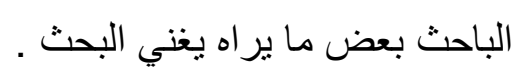

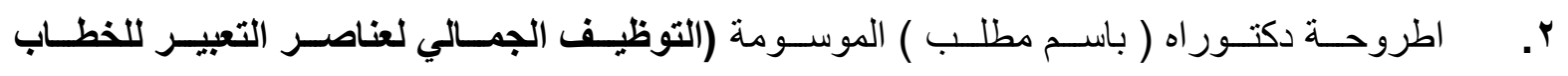
السينماتوغرافي. في الفيـــم الروائسي القصير) لتناولها بعض المفاهيم الخاصـة للرؤى المتعددة للنص الواحد

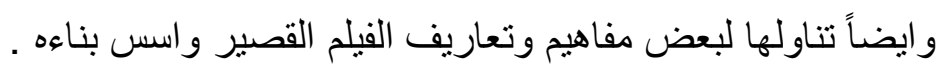

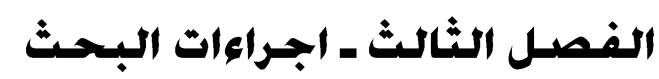

أولاً : مـنهج البحث : اعتمـد الباحث في موضـوع ( تعـد الرؤى الاخر اجيـة للموضـوعة الواحدة في الفلم القصبر) على المنهج الوصفي الذي ينطوي على التحليل وذللك لتحقيق اهداف البحث . ثانياً : مجتمع البحث : تحدد مجتمع البحث بـالافلام التي انتجتها شركة (BOMBAY SAPPHIRE) في سنة r ا • r و هي خمسة افلام منها اختار الباحث اربعة للتحليل . ثالثاً : عينات البحث : اختار الباحث العينات كونها تحقق هدفه بشكل قصدي والعينات هي :

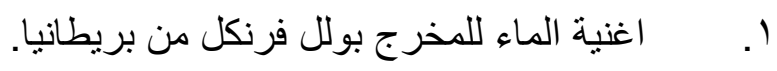
r. السلطعون للمخرج كادي كاتلو من استر اليا .

r. السيد ، للمخرج شيخار باسي من المانيا .

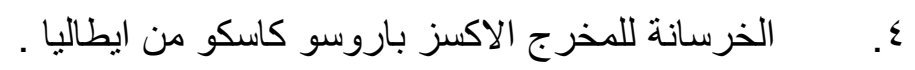

رِابعاً : اداة البحث : قام الباحث بتحديد أداة يتم الاستناد أليها في تحليل العينة المختارة من مؤشرات الإطـار

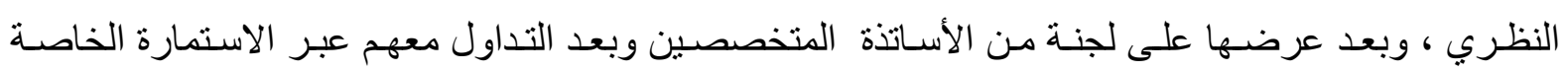
بالاستبيان وكما هو مثبت في قائمة ملاحق البحث . 
خامسـاً : صدق الاداة : لتحقيق اعلى قدر من الصدق لاداة بحثَه قام الباحث بعرض المؤشر ات على لجنـة الخبراء وقد اظهر السادة الخبر اء نسبة الاتفاق على فقرات الآر اء بـ(01 \%) وبذللك حقّق الباحث صدق الاداة بحساب الاتفاق بين السادة الخبر اء وفق معادلة كوبر في ادناه معادلة كوبر = عدد مرات الاتفاق

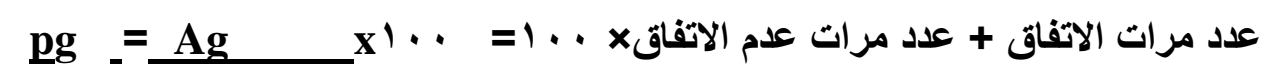

\section{Ag + dg}

سادسـاً : وحدة التحليل : اعتمد الباحث على المشـهـ واللقطـة كوحدة لتحليل الافلام من اجل الوصـول الىى مضمون عينة البحث . مان.

\section{سابعاً : التحليل

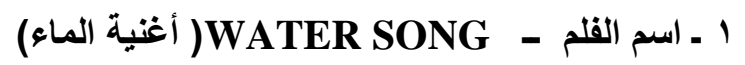 \\ سيناريو وإخراج - بولل فرنكل \\ BOMBAY SAPPHIRE - انتاج

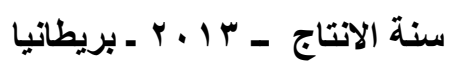 \\ ملنمص النفيلهم}

يتحدث الفلم عن فتـاة شـابة تخسـر في السباحة مـع منافسـة فتـاة وحيدة تفوز عليها باستمر ار تثـعر

بالاحباط رغم تشجيع المدربة لها في احدى اللحظات وقبل ان تخرج من المسبح تشـاهد مدربتها مـع الفتاة التي تفوز عليها بالسباق تجلس على الاريكة وتقابلها المدربة كأنها تفحصها تتراجع الى الخلف وتخفي نفسـها بالظل الى ان تخرج المدربة من الغرفة تدخل هي الى الغرفة ولا تجد الفتاة التي كانت مستلقية على الاريكة وتتــاهد صندوق صغير من القماش وضـع على طرف الاريكة تقترب منهه وفي هذه الاثتـاء تدخل المتدربـة تنتبه اليها وتنألها عن الصندوق ومالذي يوجد في داخله تجيبها المتدربة ولا شي وتطلب منها ان لاتفتحه لكن الفتاة تصر على فتحه رغم تحذيرات المتدربة وقو لها لها بانها سوف تندم على فتحه ضناً منها بان سر فوز صديقتها عليها يكمن في فتح هذا الصندوق ما ان تفتحة حتى ننتقل الى مشهد في عمق الماء يمتزج مع لقطات من السباق تفوز

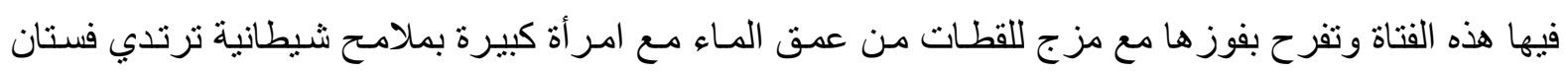
احمر فضفاض تقدم قنينة فيها سائل احمر الى القتاة التي كانت ترندي فستان ابيض ومن خـلال الانتقال السريع ولقطات متعددة تظهر احدى اللقطات هذه المر أة الكبيرة صـاحبة الزي الاحمر تحساول ان تغرق الفتاة وتسحبها

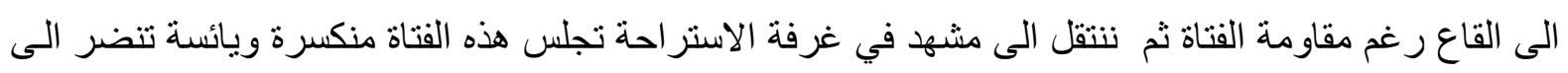
الاسفل تجلس قربها المدربة وتقول لها هل انت سعيدة الان لمـا لم تصدقيني تقف يتبادلان الكلام ثم ثقف الفتاة

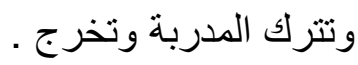

المؤشـر الاولـ (تعميق المعنى ، وهو الجاتب الأكثر أهميـة في تحديد رؤيـة المخرج السينمائي من حيث توظيفه لعناصر اللغة السينمائية) 
تجسد ذللك في لقطات متنو عة الاول كان على الفتاة التي كانت تجلس على الاريكة مقابل المتدربة عندما خرجت المدربـة ودخلت البطلة لم تجد الفتاة التي كانت مستلقية قبل لحظـات تعبير اً عن انها شربت السـائل الاحمر فحققت الفوز وماتت نفس السائل الذي منحته المرأة الكبيرة الى البطلة في مـا بعد وكذلك ورد في الفيلم معنى عميق تجسد في ملابس المر أة الكبيرة الحمر اء و الفضفاضـة و المكيـاج حيث برزت ملامحها بشكل حاد بسو اد حول العين وبعض الاوشام الصغيرة خلف الاذن كأنها ملامح شيطانية ، و القنينة الزجاجيـة الصغيرة التي تحتوي على سائل احمر شفاف التي قدمتها المر أة الكبيرة ذات الملامح الثيطانية الى الفتاة لون السائل يشبه الدم فثرب السـائل يعنـي الموت هذا هو المعنى الذي اراد المخرج ايصـاله ، وملابس البطلاة البيضـاء الفضفاضـة وتسريحة شعر ها كأنها عروس كانت ذات معنى ايضاً عن صغر سنها وبر اءتها ، اما الصوت فكان مميز بشكل ملفت حيث ان لايوجد هناك اصو ات طبيعية كلها تلاعب بها المخرج و اضافت بعداً و عالمـاً اخر وكأنه يريد ان يقول لنا هذا عالم ثان الذي تجري في الاحداث و المعنى الاعمق جاء ي نهاية الفلم وبعد ان البسوها قلادة الفوز بالمركز الاول نظرت الى السماء بابتسامة خفيفة كانها تعترف بانها مسؤولة عن فعلتها و هي التي ارادت ذلك فدفعت الثمن وهو الموت.

المؤشر الثاني - (ان لكل مخرج سينمائي شكلاً مبتكرأ يختلف عن الاخر في تناول مفردات اللغة السينمائية وهي كل

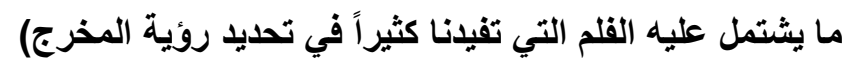
على مستوى التصـوير فاستخدم المخرج اغلب لقطـات الفلم بالكامير ا المحمولة مـع اهتز ازات خفيفة تعبير اً عن حالة القلق والتوتر التي كانت تعيشها البطلة في صر اعها من اجل الفوز ، وكذللك استخدم المخرج القطع السريع والانتقال العشوائي بين اللقطات يكسر فيه الزمان و المكان وتنو عت احجام اللقطات وطغت اللقطة القريبة في الفيلم حيث ان المخرج حاول ابراز بعض التفاصيل وملامح الثخصية في حالات التوتر والقلق امـا على مستوى المونتاج فتقنية التصـوير البطيء كانت واضحة في الفيلم لأسباب جمالية حيث ان الفيلم اغلب مشاهده مصورة من قاع الماء فأبطاء الصورة يضيف جمالية الى الصورة، ويسـاعد على التركيز فيمـا يريد ان يقوله المخرج فيثير انتباهنا اليه عن طريق الابطاء و هذا يخص الاسباب الدرامية وكذلك لم يستخدم المخرج الخدع السينمائية حيث تم تصوير الفيلم بالكامل في مكان واحد يضم حوض السباحة وغرفة الملابس وغرفة المدربة حتى مشاهد الغرق كانت مصورة في قاع حوض السباحة ، و الموسيقى لم تفارق المشـاهد الا قليلاً جداً فقد اعطت تعبير اً جمالياً ودر امياً كان واضحاً خاصة في المشـه الذي كانت تر اقب الفتاة المتدربـة في غرفتها وهي تعالج القتاة الاخرى في الدقيقة الثانية من الفلم ، والعنصر الاخير من عناصر اللغـة السينمائية الذي لعب دوراً مهماً في الفيلم على المستوى الدرامي في المشهـ الثاني من الفيلم في الدقيقة الثانيـة عندما كانت الفتاة تر اقي المدربة فالاجو اء كانت مظلمة الا بعض الاضاءة الخفيفة المحسوسة على الحواف تعبير اً عن ان مـا تقوم به الفتاة يثير الثـك وفيه غموض وان هنالك خطأ مـا جسده المخرج من خـلال الاضـاءة بشكل مميز رغم ان الحوار هو نفسه في كل الافلام نفس الجمل لكن هذا المخرج كان لله معالجة مختلفة لقول الجمل وهي من خـلال الاشارة وحركة الثفاه رغم ان الثخصيات قادرة على النطق . 
المؤشر الثالث - (التكوين بوصفه مصدراً مهماً للمعلومات والإيحاءات ، والذي يقصد بـه كل مـا موجود داخل اللقطة ولا يقصد به تحديد التكوين التثكيلي لللقطة بقر ما هو طبيعة استخدام عناصر التعبير السينمائية): في الدقيقة الر ابعة من الفيلم وعند اول ضهور للمر أة الكبيرة ذات الملابس الحمر اء الفضفاضـة قام المخرج بتصوير ها بلقطات تحت مستوى النظر بزو ايا مختلفة وبتقنية السلوموشن تعبير اً عن سيطرة هذه المر أة وقوتها وضعف البطلة بالمقابل .وكذلك في الدقيقة (r) (0) وضف المخرج احد المصادر الضوئية في عمق الكادر الذي كان على شكل هالة ضوئية اتجهت لها الفتاة عندما خسرت كل شيء فهي بذهابها نحو الضوء تعبير اً عن ذهابها الى الموت او الى عالم

ثاني هي اختارته بنفسها عندما فتحت الصندوق .

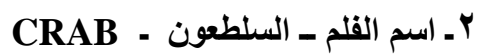
سيناريو واخراج ـ كادي كاتلو - BOMBAY SAPPHIRE

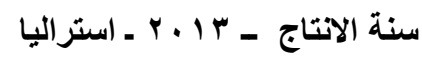
ملخص القلم

تدور قصة هذا الفيلم حول اثثين من السلطعون في جرف البحر وفي يوم مشمس احدهم وهو الاصـر باللون الاصفر يتجول على الرمال يثـاهد قنينة مغلقة يقترب منها ويحاول ان يلمساها يقترب منه السلطعون الاخر ويحذره

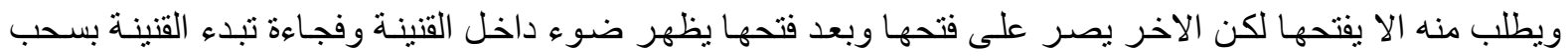
الاشياء الىى الداخل وتسحب كل شيء من رمال وماء وكو اكب وحيو انات وكل شيء الا السلطعون ويصبحون في العدم او فضاء يخلو من كل شيء الا منهم والقنينة حيث لا جاذبية و لا ارض و لا سماء فجأة يضرب احدهم القنينة من الخلف وتخرج سمكة قرش الى الفضاء وتهاجم السلطعون الاخر وتأكله وما ان تتجه الى الثاني لتأكله حتى يضـع القنينة في فم

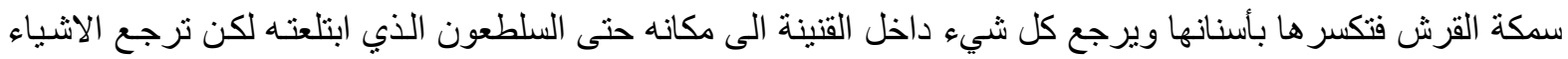

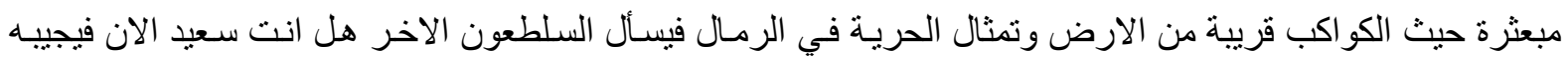
بنعم ثم بعد بر هة ينتبه السلطعون الثاني الذي كان معترضاً على فتح القتينة يذهب الى قنينة اخرى تثبه الاولى ويحاولون التجربة مرة ثانية من خلال فتح القنينة.

المؤشر الاول - (تعميق المعنى ، وهو الجانب الأكثر أهميـة في تحديد روئية المخرج السينمائي من حيث توظيفه لعناصر اللغة السينمائية): في الدقيقة الثالثة من الفلم وبعد ان عـادو الى الارض نتيجة كسر الزجاجـة في فهم سمكة القرش لم يرجع كل شيء الى مكانه بالضبط حيث لاحظنا ان كوكب المريخ قريب جداً من الارض و القمر وبقيـة الكواكب ايضاً كلها قريبة من الارض وكذلك تمثال الحرية مرمي في احد الاركان على الرمال في العمق والبرج الثـهير في فرنسا ايضاً في جرف النهر و الكثير من الحاجات واللافتات كلها مرمية بشكل عبثي ، فالمعنى المتضمن في هذه اللقطات او المشهح هو بعد ان نتعرض الى هجوم او سيطرة من قبل فئة معينة لا نعود كما كنا يختل النظام وتسود الفوضى وضف المخرج ذلك باستخدام عناصـر اللغـة السينمائية من خـلال الديكور والاكسسوار بشكل

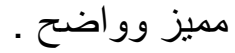
المؤشر الثاني - (ان لكل مخرج سينمائي شكلاً مبتكراً يختلف عن الاخر في تناول مفردات اللغة السينمائية وهي كل ما يشتمل عليه القلم التي تفيدنا كثيراً في تحديد روئة المخرج) 
ان اول شيء يميز هذا المخرج عن غيره هو ابتعاده عن الواقعية وذهابه الى التقنية الحاسوبية وتصنيع

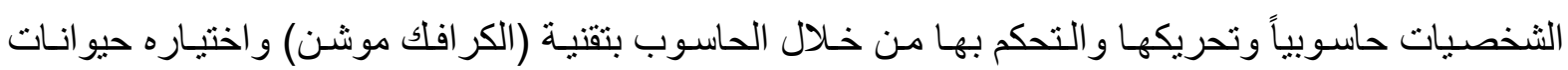

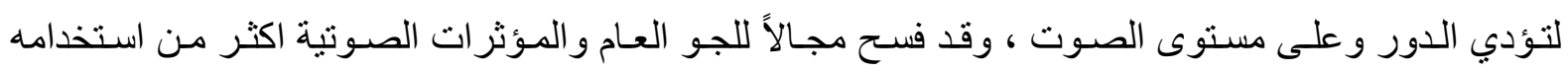
للموسيقى والحوار ايضاً كان مميزاً وجمله كانت الثخصيات تتطقها ببطء كأنما تأتي على لسـان طفل اللقطات كانت طويلة وقليلة لكنها لم نسبب الملل فالقطع كان يأتي في الوقت المناسب وتنو عت احجام اللقطات وان المخرج حـاول ابر از بعض التفاصيل مـن اكسسوار او ردة فعل لاحد الثخصيات مـن خـلال اللقطـة القريبـة وكذلك استخدم اللقطات العامة التعريفية التي تكثف المكان الذي تدور فيه الاحداث وهي اللقطة الاولى في الفيلم المؤشر الثالث - (التكوين بوصفه مصدراً مهماً للمعلومات والإيحاءات ، والأي يقصد به كل مـا موجود داخل اللقطة ولا يقصد به تحديد التكوين التثكيلي لللقة بقدر ما هو طبيعة استخدام عناصر التعبير السينمائية): في الدقيقة (rr:r) بيين لنا المخرج ان مـا قام بـه السلطعون الاصفر شيء مسلي وقبل ان بقرروا ان يعيدوا الكرة مرة اخرى بفتح قنينة اخرى مرمية على احد الجوانب في الرمل اظهر لنا المخرج لقطة عامـة من الخلف تجمع الحيوانات وهي تتظر الى الفوضى التي ارتكبها احدهم نتيجـة فتحة للقنبـة يحـاول ان يقول لنـا قبل ان يقول الى صديقه انا اذا قمنا بفتح القنينة مرة اخرى سنحصل على فوضى اكبر من هذه .

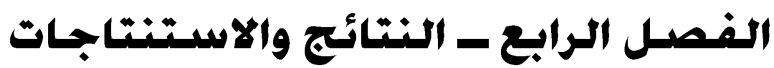

النتائج :

ان الاستخدام الصحيح لعناصر الاشتغال السينمائية يدعمان فكرة المخرج فيما ينعلق بالمعنى المتضمن في الفلم

$$
\text { و هذا ما لاحظناه في فيلم (اغنية الماء) وفيلم (السيد). }
$$

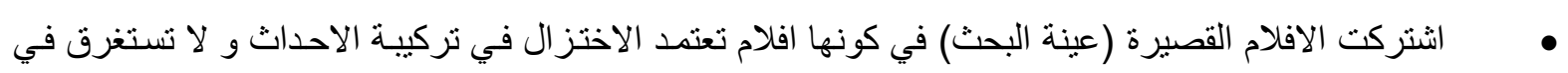

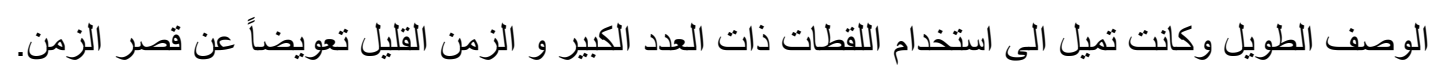
التركيز على الثخصية بشكل و اضح من خلال الصورة والصوت وصو لا إلى تحقيق رؤية المخرج التي تعزي الفكرة العامة للفلم .

• ملت مقدمات الافلام القصيرة (عينة البحث ) جميعها مقدمات مهمة منها مـا خالف نوقع المشـاهد مثل فيلم

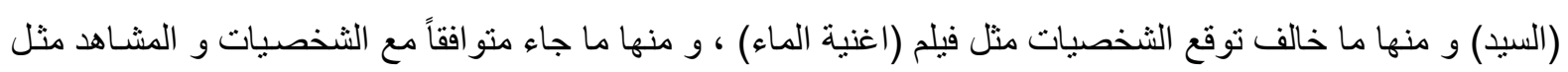
فيلم (السيد).

• تميزت الافلام القصيرة بوجود عنصر التجريب من خلال الجرأة التي تناول بها المخرجون مواضيعهم كون جميع المخرجين من الهواة وغير محترفين .

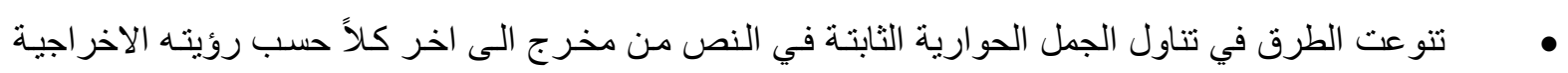
وحسب تفسيره للنص.

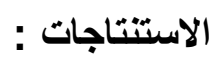
اعتمد المخرجين بشكل كبير في التجسيد على التصوير واهملو المونتاج فهنالك قدرة للمونتاج ان يخلق الصدمة والار هاف السايكولوجي كلها كانت غير ملتفت اليها في كل العينات وهذا واضح جدا من خلال التحليل. 
ان لكل مخرج من المخرجين يمتلك طريقته التي تختلف عن نظيره ، لذا نقف على طرق و أسـاليب بعدد المخرجين، يقابلها عدد المعالجات و عدد من الرؤى .

ان كل مخرج اضاف قيمة الى الفلم فهو يستخدم الأدوات السردية في رسم الثخصية و الحبكة والبنـاء

القصصي لكي يعطي قر اءة ذات مستويات متعددة للنص ومن خلال فكرته الاخر اجية يقوم المخرج بالجمع بين التصوير و أداء الممثلين وقر اءة النص لكي يخلق معنى متضمناً يضيف بدوره عمقاً لتجربـة مشـاهدة الجمهور للفيلم.

ان كل مخرج يجب ان تكون لديه فكرة اخر اجيـة يعمل على تنفيذها باستخدام قدر اتهه في الإخر اج في

تفسير النص ، وتجسيده من خلال عناصر الاشتغال كل ذلك في توازن مع اهتمامات المخرج ومهارته ان تصميم الأسلوب المونتاجي في استخدام اللقطات يجعل من تفسير النص وأداء المثللين متكاملين مـع

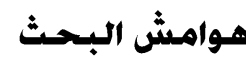

يوسف معلوف ، المنجد في اللغة ، (المكتبة المصرية العامة ، القاهرة) صع ب؟

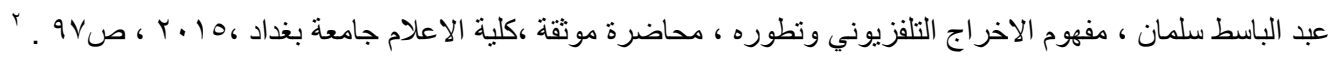

المصدر السابق نفسه ، ص ص

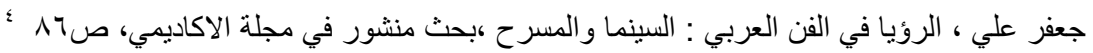

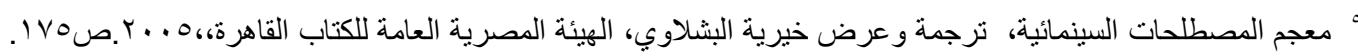

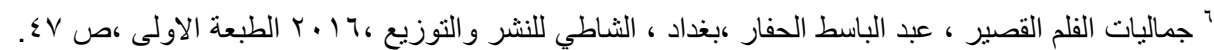

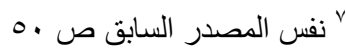

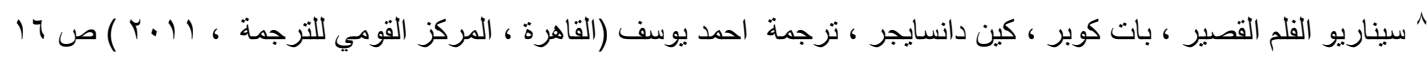

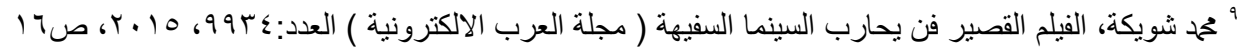

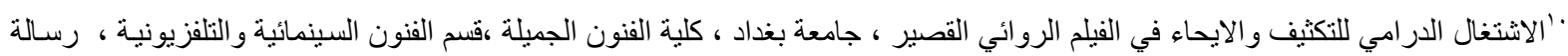

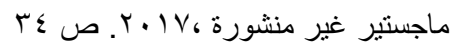

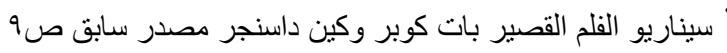

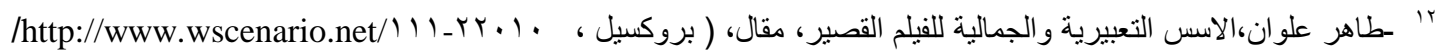

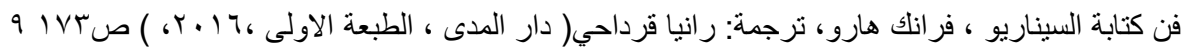

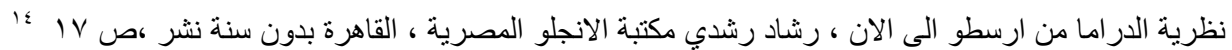

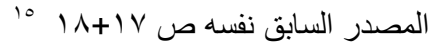

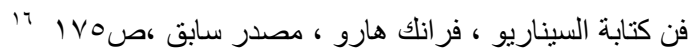

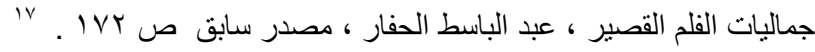

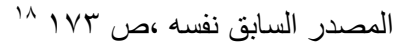

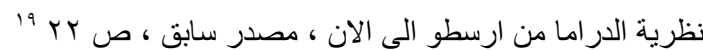

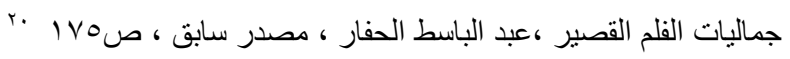

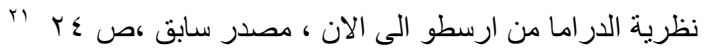

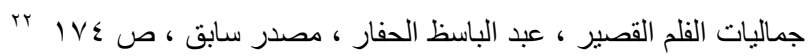

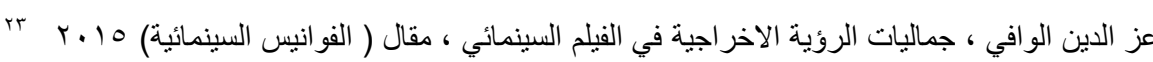

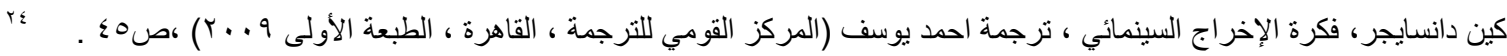




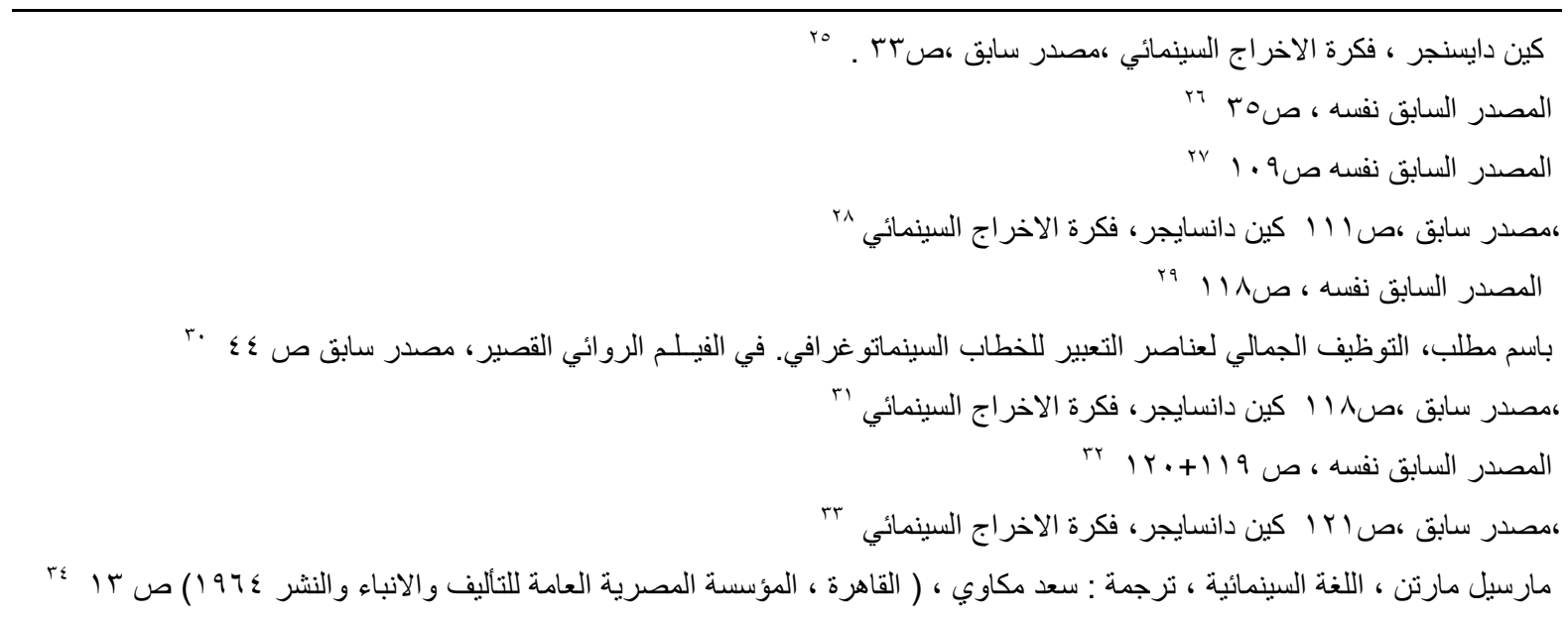

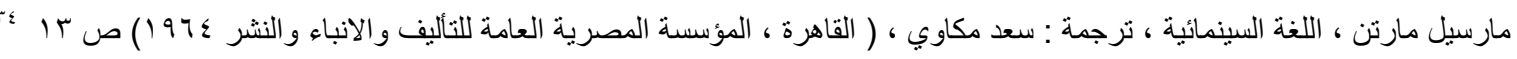

القزءعان الكريم:

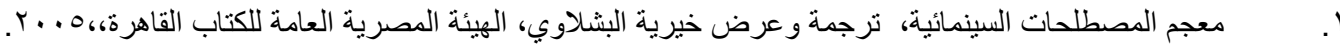

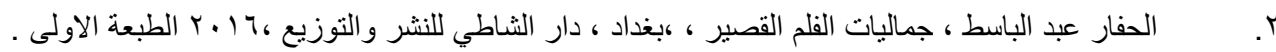

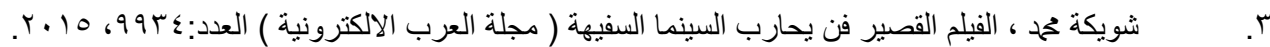

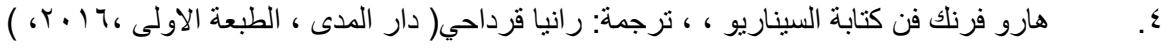

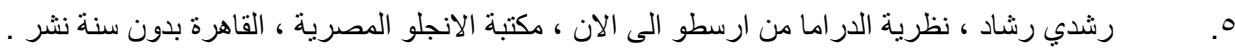

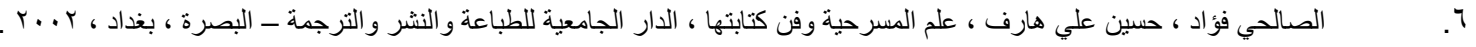

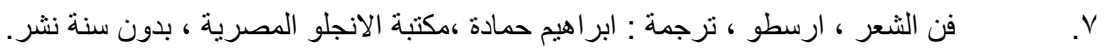

^. اجري لاجوس فن كتابة المسرحية ، ترجمة :دريني خشبة ، (مكتبة الانجلو المصرية ، القاهرة ، بدون سنة نشر ) )

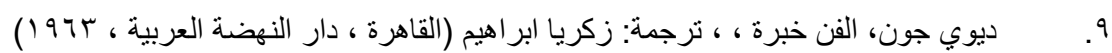

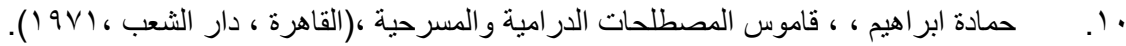

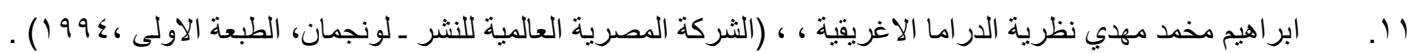

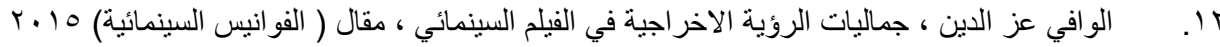

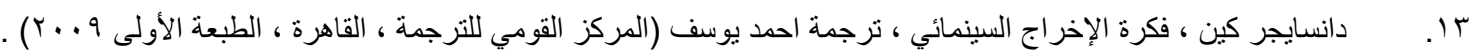

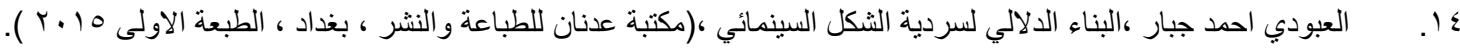

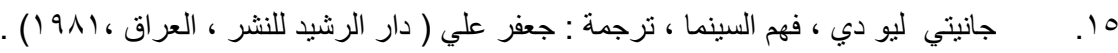

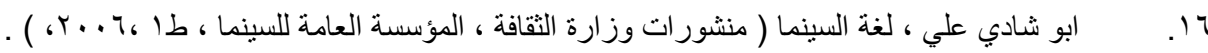

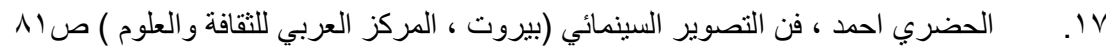

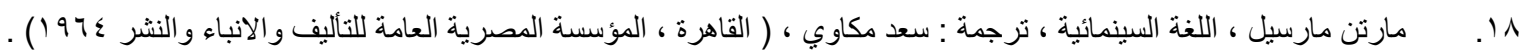

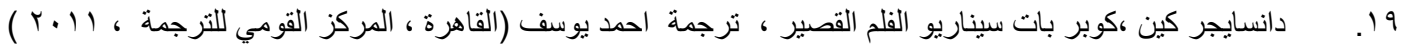

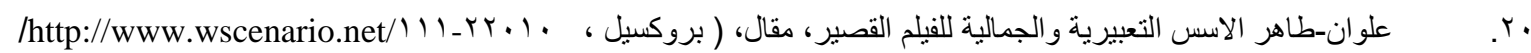

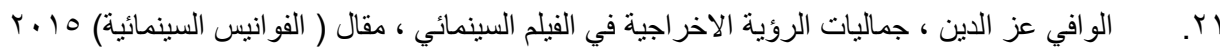

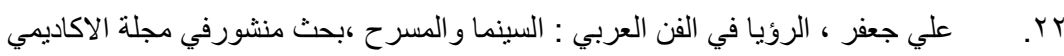

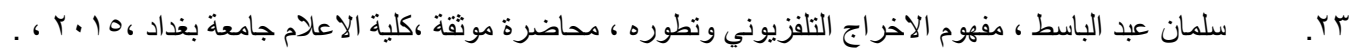

المصادر من الرسائل والاطاريح : التصن

ا. التوظيف الجمالي لعناصر التعبير للخطاب السينماتوغرافي. في الفيـلم الروائي القصبر، باسم مطلب ، اطروحة دكتوراه ،غير

منشورة (كلية الفنون الجميلة ، قسم الفنون السينمائية والتلفزيونية )

Y. الاشتغال الدرامي للتكثيف والايحاء في الفيلم الروائي القصبر ، جامعة بغداد ، كلية الفنون الجميلة ،قسم الفنون السينمائية والتلفزيونية

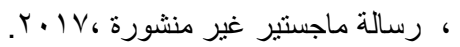

